American Journal of Applied Sciences 2 (7): 456-464, 2007

ISSN 1546-9239

(C) 2007 Science Publications

\title{
The Fate of Non-Volatile Organic Chemicals in The Agricultural Environment
}

\author{
${ }^{1}$ Mohammad A. Batiha, ${ }^{1}$ Abdul Amir H. Kadhum, ${ }^{1}$ Zahedi Fisal, ${ }^{1}$ Abu Bakar Mohamad, \\ ${ }^{1}$ Wan R.W. Daud, ${ }^{1}$ Mohd S. Takriff and ${ }^{2}$ Marwan M. Batiha \\ ${ }^{1}$ Department of Chemical and Processes Engineering, Faculty of Engineering, \\ National University of Malaysia, 43600 UKM Bangi, Selangor, Malaysia \\ ${ }^{2}$ Deprtement of Science, Faculty of Science and Agriculture, Jerash Private University, \\ 26150, P.O. Box 311, Jerash, Jordan
}

\begin{abstract}
Multimedia dynamic model of the fate of non-volatile organic chemicals (NVOC) in the agricultural environment is described. The modeled environment, consisting of up to three major surfaces environmental compartments, includes air, agricultural soil, and surface water. This model is based on the aquivalence approach suggested by Mackay and co-workers in 1989. As the movement of chemicals in the environment is closely associated with the movement of air, water and organic matter, the complete steady state mass budgets for air, water and particulate organic carbon (POC) between the model compartments are described. All of the model equations, which are expressed in aquivalence notation, the mass balance for NVOC in the environmental surfaces compartments at dynamic state, and equations for the calculation of partitioning, overall persistence, total amount, total concentrations at dynamic state and intermedia fluxes of organic chemicals between air, water, and soil at steady-state are provided.
\end{abstract}

Keywords: Non-volatile organic chemicals; Aquivalence; Multimedia model; Dynamic; Partitioning

\section{INTRODUCTION}

Organic pollutants from the agricultural environment can enter the atmosphere by a variety of different routes, particularly from direct discharges, wind erosion of soil or volatilization from soil or water ${ }^{[1,2]}$. Upon entry into the atmosphere, pollutants are transported and distributed over long distances, through wet and dry processes ${ }^{[3,4]}$. However, if the pollutants enters the environment, two groups of processes affect its fate: (i) transport and transfer processes that move a chemical among ecosystem compartments and away from the emission point, include sorption, volatilization ${ }^{[5]}$, runoff $^{[6]}$, and leaching ${ }^{[7]}$, and (ii) degradation processes that convert chemical to transformation products ${ }^{[8]}$ include photo, chemical and microbial degradation ${ }^{[9]}$. Predicting the fate of organic pollutants released into the environment is necessary to anticipate, and thereby minimize, adverse impacts away from the point of emission. This means that we must understand what happens to a chemical once it has been emitted, and we must be able to forecast its behavior in the environment. Using this information, the probable adverse impacts on the environment and on human health can then be estimated.

The multimedia fate and transport models (MFTMs) have been developed and used for many years to simulate the fate of such contaminants, such as the influence of forests on the overall fate of semivolatile organic compounds ${ }^{[10]}$; urban area model $^{[11]}$; the great lakes region $(\mathrm{CHEMGL})^{[12]}$; coastal zone model for persistent organic pollutants (CoZMoPOP 2$)^{[13]}$. These models are fugacity-based, which are valid for most volatile organic pollutants and very hydrophobic compounds.

Many of the chemicals used in agricultural activities are considered environmentally non-volatile (e.g., glyphosate; paraquat; bentazon) that is, they do not partition appreciably into air. The fate and transport processes of non-volatile organic chemicals (NVOC) in the agricultural environment at dynamic or even at steady-state conditions are not obvious yet. The purpose of this paper is to develop multimedia fate and transport model of NVOC in the agricultural environment at

Corresponding Author: Mohammad A. Batiha, Department of Chemical and Processes Engineering, Faculty of Engineering, National University of Malaysia, 43600 UKM Bangi, Selangor, Malaysia 
dynamic conditions. In the following context model description is provided.

\section{MODEL STRUCTURE}

Current model is based on the dynamic Level IV aquivalence model developed by Mackay and coworkers ${ }^{[14]}$. The basic concept of the aquivalence approach are fully described elsewhere ${ }^{[14-18]}$, and are only briefly summarized here. This approach is used to estimate NVOC fate on a various scales. Below we describe modifications to the Level IV model to allow its application to agricultural environment for NVOC.

Model compartments: A typical MTFM divides the environment into a number of boxes or compartments, which are considered well-mixed and homogeneous with respect to both environmental characteristics and chemical contamination ${ }^{[18]}$. These environmental compartments are then linked by a variety of intercompartmental transfer processes ${ }^{[13]}$. Current model comprise three bulk compartments (Fig. 1): air (A), surface water (W), and agricultural soil (S). These compartments are linked by up to seven transport processes from $X$ to $Y$ medium $\left(D_{X Y}, m^{3} / h\right)$. Chemical can enter air and water through advection. Chemical can also enter each medium $\mathrm{X}$ through a direct emission, $\mathrm{E}_{\mathrm{X}}(\mathrm{mol} / \mathrm{h})$. Each bulk compartment consists of pure and particulate-phases of specified volume. Chemicals are assumed to be in equilibrium between these phases within each bulk compartment (e.g., between dissolved and suspended particulate-phases within water). Chemical can transfer among compartments and can be lost from all compartments through various transformation processes ${ }^{[11]}$.

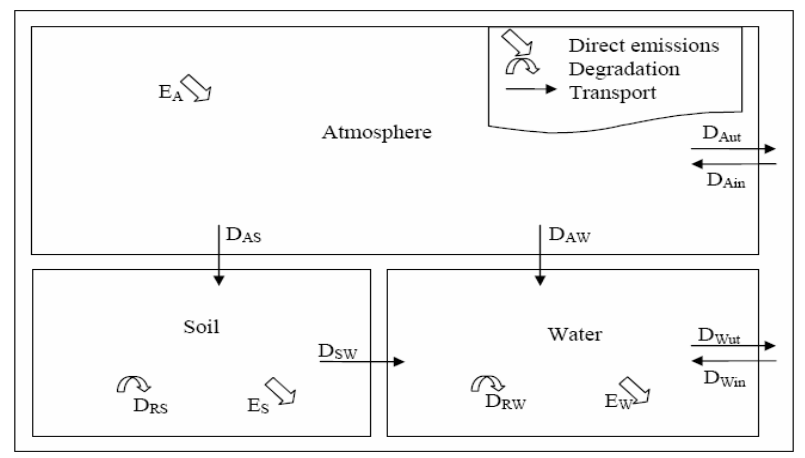

Fig. 1: Schematic representation of the environmental compartments and contaminant fate processes

Transfer fluxes of contaminants: The movement of chemicals in the environment is closely associated with the movement of air, water and organic matter. In the current model, advective inter-compartmental transfer fluxes for the contaminants are calculated as the product of a flux of a carrier phase $G$ in units of $\mathrm{m}^{3} / \mathrm{h}$, namely air $\left(G_{a}\right)$, water $\left(G_{w}\right)$, and particulate organic carbon $\left(\mathrm{G}_{\mathrm{P}}\right)$, and a contaminant concentration $(\mathrm{C})$ in that phase in units of moles $/ \mathrm{m}^{3}$. Solving the contaminant mass balance thus requires the construction of mass balances for air, water and particulate organic carbon (POC) within the modeled system. In contrast to the fluxes of the contaminants, the fluxes of these carrier phases were assumed by to be constant in time. In the following, details are provided for the construction of mass balances for air, water, and POC at a steady state situation.

Mass balance of air: With only one atmospheric compartment and one advection rate in and out of the model region, the mass balance for air, $\left(\mathrm{m}^{3} / \mathrm{h}\right)$ is calculated using Eq. (1) in Table 1. In this equation, $V_{A}$ is the volume of atmospheric compartments in $\mathrm{m}^{3} ; \tau_{\mathrm{A}}$ is the atmospheric residence time in $\mathrm{h}$, which calculated as: $\tau_{\mathrm{A}}=\frac{\mathrm{L}_{\mathrm{A}}}{\mathrm{WS}}$

where $\mathrm{L}_{\mathrm{A}}$ is the length of atmospheric compartment, $\mathrm{m}$, and WS is the wind speed, $\mathrm{m} / \mathrm{h}$.

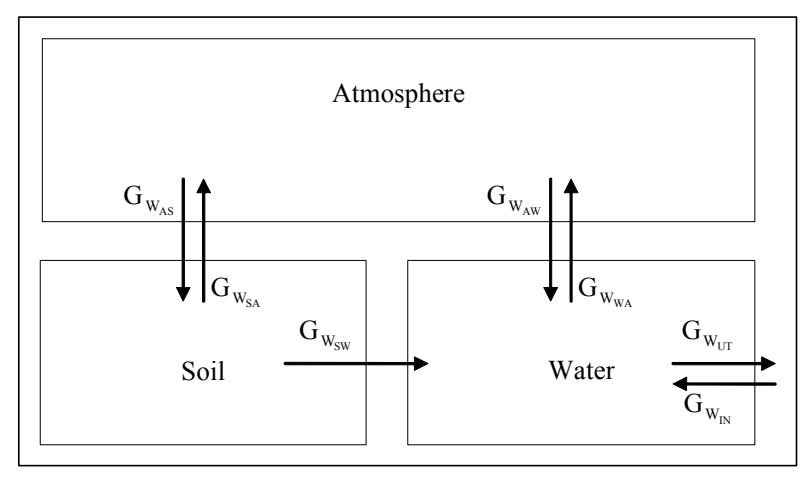

Fig. 2: Water fluxes between the model compartments

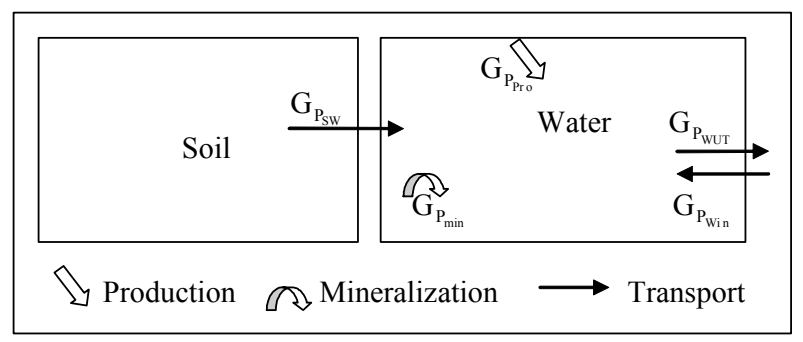

Fig. 3: POC budget for the soil and water compartments 
Mass balance for water: A complete steady state water balance is formulated for the model region, i.e. a consistent set of up to 7 inter-compartmental water fluxes, $\mathrm{G}_{\mathrm{W}}$, between modeled compartments (Fig. 2). The water flux to soil compartment by precipitation, $\mathrm{G}_{\mathrm{W}_{\mathrm{AS}}}$ in $\mathrm{m}^{3} / \mathrm{h}$ (Eq. (2) in Table 1), is estimated from rain rates for the terrestrial environment $\left(U_{S}, m / h\right)$, and the surface area of terrestrial compartment $A_{S}, m^{2}$. By analogy with $\mathrm{G}_{\mathrm{W}_{\mathrm{AS}}}$, the water flux to aquatic compartment by precipitation, $\mathrm{G}_{\mathrm{W}_{\mathrm{AW}}}$ in $\mathrm{m}^{3} / \mathrm{h}$ (Eq. (3) in Table 1), is a product of the rain rates for the aquatic compartment, $U_{W}$ in $\mathrm{m} / \mathrm{h}$, and its surface area, $A_{\mathrm{W}}$ in $\mathrm{m}^{2}$. Evaporation loss from soil compartment, $G_{\mathrm{W}_{\mathrm{SA}}}$ in $\mathrm{m}^{3} / \mathrm{h}$

(Eq. (4) in Table 1) is estimated employing fractions $\phi_{\mathrm{S}}$ of the total water flow to soil compartment that evaporates from that compartment. Thus, by analogy with $\mathrm{G}_{\mathrm{W}_{\mathrm{AW}}}$, the evaporation from water compartment, $\mathrm{G}_{\mathrm{W}_{\mathrm{WA}}}$ in $\mathrm{m}^{3} / \mathrm{h}$ (Eq. (5) in Table 1) in this equation, $\phi_{\mathrm{W}}$ is the fraction of the total water flow to water compartment that evaporates from that compartment. The inter-compartmental water fluxes are then derived as the balance of input by precipitation and run-off and loss by evaporation. Thus, the run-off flux from soil compartment, $\mathrm{G}_{\mathrm{W}_{\mathrm{SW}}}$ in $\mathrm{m}^{3} / \mathrm{h}$ is calculated using Eq. (6) in Table 1. The net flow between water compartment and outside, $\mathrm{G}_{\mathrm{W}_{\mathrm{NUT}}}$ in $\mathrm{m}^{3} / \mathrm{h}$ is calculated using Eq. (7) in Table (1). Finally, in the water compartment, $\phi_{\mathrm{W}}$ is defined as the fraction of net water input to a downstream compartment that evaporates from that compartment, whereas $\phi_{\mathrm{G}_{\mathrm{wUT}}}$ is a factor by which the water flux in the water compartment is increased by inflow from the soil compartment. However, the water flows from water compartment to outside, $\mathrm{G}_{\mathrm{W}_{\mathrm{UT}}}$ in $\mathrm{m}^{3} / \mathrm{h}$ is calculated using Eq. (8) in Table 1, and the water flow from outside to water compartment, $\mathrm{G}_{\mathrm{W}_{\mathrm{IN}}}$ in $\mathrm{m}^{3} / \mathrm{h}$ is calculated using Eq. (9) in Table 1.

Mass balance for particulate organic carbon: Both within the soil and water compartments, many organic contaminants attach themselves preferentially to organic material, and transport of contaminants between virtually all environmental media can be mediated through organic matter ${ }^{[13]}$. In the current model, a complete steady state mass balance for organic matter is formulated for the model region, i.e. a consistent set of up to five POC production, transport and mineralization rates, $\mathrm{G}_{\mathrm{P}},\left(\mathrm{m}^{3} \mathrm{POC} / \mathrm{h}\right)$ (Fig. 3).
Specifically, the concentration of POC in the water compartment, $\mathrm{C}_{\mathrm{PW}}$ in $\mathrm{g} / \mathrm{m}^{3}$ is calculated from the balance of these processes. Even though they are not required for the contaminant mass balance, rates of primary production and POC mineralization are also calculated to complete and assure the consistency of the mass balance. Required parameters for construction of these mass budgets are: (i) the water fluxes, $\mathrm{G}_{\mathrm{W}}$, (ii) the concentration of POC in the water flowing into the model domain in $\mathrm{g} / \mathrm{m}^{3}, \mathrm{C}_{\mathrm{PIn}}$, and (iii) the mineralization rate in the water compartments as fraction of the primary productivity in $\mathrm{h}^{-1}, \phi_{\min }$. Wania et al. 2006 have derived the POC concentrations and fluxes as following:

The inflow of POC from soil to water (Eq. (10) in Table 1), $G_{P_{S W}}$ in units of $\mathrm{m}^{3} / \mathrm{h}$ is calculated as a product of the run-off flux from soil compartment $\mathrm{G}_{\mathrm{W}_{\mathrm{SW}}}$, and the volume fraction of solids in soil run-off, $v_{\mathrm{SS}}$. The volume fraction of solids in soil run-off is calculated from the mass fraction of organic carbon using:

$$
v_{\mathrm{SS}}=\frac{1}{1+\frac{\left(1-\mathrm{m}_{\mathrm{S}}\right) \cdot \rho_{\mathrm{OC}}}{\mathrm{m}_{\mathrm{S}} \cdot \rho_{\mathrm{mm}}}}
$$

where $m_{S}$ is the mass fraction of organic carbon in solids of soil compartment, $\rho_{\mathrm{OC}}, \rho_{\mathrm{mm}}$ are the density of organic carbon and mineral matter in units of $\mathrm{g} / \mathrm{m}^{3}$.

The primary POC production in the aquatic compartment, $\mathrm{G}_{\mathrm{P}_{\mathrm{Pr}}}$ in units of $\mathrm{m}^{3} / \mathrm{h}$ is calculated using Eq. (11) in Table 1 . In this equation, $\mathrm{P}_{\mathrm{W}}$ is the primary productivity in the aquatic compartment, $\mathrm{g} \mathrm{POC} /\left(\mathrm{m}^{2} \mathrm{a}\right)$, $A_{W}$ is the surface area of aquatic compartment, $\mathrm{m}^{2}$. The POC mineralization in the aquatic compartment (Eq. (12) in Table 1), $\mathrm{G}_{\mathrm{P}_{\min }}$ in units of $\mathrm{m}^{3} / \mathrm{h}$ is calculated as a fraction of the primary productivity. The calculation of the POC fluxes in and out of the aquatic compartment, followed by simultaneous solution of the POC mass balance over this water compartment to yield concentrations of $\mathrm{POC}$ in water $\left(\mathrm{C}_{\mathrm{PW}}\right)$, which calculated using Eq. (13) in Table 1. In this expression, $\mathrm{C}_{\mathrm{PIn}}$ is the concentration of POC in the water flowing into the model domain in units of $\mathrm{g} / \mathrm{m}^{3}$. $\mathrm{C}_{\mathrm{PW}}$ will be needed in the later calculation to calculate the phase partitioning in the aqueous system.

Description of contaminant fate: Unsteady-state conditions give differential equations in time. The simplest method of sitting up the equation is to write:

$$
\frac{\mathrm{d}(\text { contents })}{\mathrm{dt}}=\text { total input rate }- \text { total output rate }
$$


Table 1 Equations used to calculate the air, water, and particulate organic carbon fluxes between the model compartments in $\mathrm{m}^{3} / \mathrm{h}$

\begin{tabular}{lll}
\hline Mass balance & \multicolumn{3}{l}{ Fluxes equations } \\
\hline Water & 1. & $\mathrm{G}_{\mathrm{A}}=\mathrm{V}_{\mathrm{A}} / \tau_{\mathrm{A}}$ \\
& 2. & $\mathrm{G}_{\mathrm{W}_{\mathrm{AS}}}=\mathrm{U}_{\mathrm{S}} \cdot \mathrm{A}_{\mathrm{S}}$ \\
& 3. & $\mathrm{G}_{\mathrm{W}_{\mathrm{AW}}}=\mathrm{U}_{\mathrm{W}} \cdot \mathrm{A}_{\mathrm{W}}$ \\
& 4. & $\mathrm{G}_{\mathrm{W}_{\mathrm{SA}}}=\phi_{\mathrm{S}} \cdot \mathrm{G}_{\mathrm{W}_{\mathrm{AS}}}$ \\
& 5. & $\mathrm{G}_{\mathrm{W}_{\mathrm{WA}}}=\phi_{\mathrm{W}} \cdot\left(\mathrm{G}_{\mathrm{W}_{\mathrm{AW}}}+\mathrm{G}_{\mathrm{W}_{\mathrm{SW}}}\right)$ \\
& 6. & $\mathrm{G}_{\mathrm{W}_{\mathrm{SW}}}=\left(1-\phi_{\mathrm{S}}\right) \cdot \mathrm{G}_{\mathrm{W}_{\mathrm{AS}}}$ \\
& 7. & $\mathrm{G}_{\mathrm{W}_{\mathrm{NUT}}}=\left(1-\phi_{\mathrm{W}}\right) \cdot\left(\mathrm{G}_{\mathrm{W}_{\mathrm{AW}}}+\mathrm{G}_{\mathrm{W}_{\mathrm{SW}}}\right)$ \\
& 8. & $\mathrm{G}_{\mathrm{W}_{\mathrm{UT}}}=\mathrm{G}_{\mathrm{W}_{\mathrm{NUT}}} \cdot\left(1+\phi_{\mathrm{G}_{\mathrm{WUT}}}\right)$ \\
& 9. & $\mathrm{G}_{\mathrm{W}_{\mathrm{IN}}}=\mathrm{G}_{\mathrm{W}_{\mathrm{NUT}}} \cdot \phi_{\mathrm{G}_{\mathrm{wUT}}}$
\end{tabular}

$$
\begin{array}{ll}
\text { 10. } & \mathrm{G}_{\mathrm{P}_{\mathrm{SW}}}=\mathrm{G}_{\mathrm{W}_{\mathrm{SW}}} \cdot v_{\mathrm{SS}} \\
\text { 11. } & \mathrm{G}_{\mathrm{P}_{\mathrm{Pro}}}=\mathrm{P}_{\mathrm{W}} \cdot \mathrm{A}_{\mathrm{W}} /\left(\rho_{\mathrm{OC}} \cdot 8760\right) \\
\text { 12. } & \mathrm{G}_{\mathrm{P}_{\min }}=\mathrm{G}_{\mathrm{P}_{\mathrm{Pro}}} \cdot \phi_{\min } \\
\text { 13. } & \mathrm{C}_{\mathrm{PW}}=\left(\mathrm{G}_{\mathrm{P}_{\mathrm{sw}}}+\mathrm{G}_{\mathrm{P}_{\mathrm{Pro}}}-\mathrm{G}_{\mathrm{P}_{\min }}+\left(\mathrm{G}_{\mathrm{W}_{\mathrm{IN}}} \cdot \mathrm{C}_{\mathrm{PIn}} / \rho_{\mathrm{OC}}\right)\right) /\left(\mathrm{G}_{\mathrm{W}_{\mathrm{UT}}} / \rho_{\mathrm{OC}}\right)
\end{array}
$$

\begin{tabular}{|c|c|c|}
\hline & Phase & Equation \\
\hline & Pure & \\
\hline 1. & Air & $\mathrm{Z}_{\mathrm{A}}=\mathrm{Z}_{\mathrm{W}} \cdot K_{\mathrm{AW}}$ (probably zero) \\
\hline 2. & $\begin{array}{l}\text { Atmospheric } \\
\text { particles }\end{array}$ & $\mathrm{Z}_{\mathrm{Q}}=\mathrm{Z}_{\mathrm{W}} \cdot K_{\mathrm{QW}}$ \\
\hline 3. & Water & $\mathrm{Z}_{\mathrm{W}}=1$ \\
\hline 4. & $\begin{array}{l}\text { Water suspended } \\
\text { particles }\end{array}$ & $Z_{\mathrm{P}}=\mathrm{Z}_{\mathrm{W}} \cdot \rho_{\mathrm{P}} \cdot K_{\mathrm{P}} / 1000$ \\
\hline 5. & Soil & $\mathrm{Z}_{\mathrm{S}}=\mathrm{Z}_{\mathrm{W}} \cdot \rho_{\mathrm{S}} \cdot K_{\mathrm{SW}} / 1000$ \\
\hline 6. & Bulk & \\
\hline 7. & Air & $\mathrm{Z}_{\mathrm{BA}}=\mathrm{Z}_{\mathrm{A}}+\mathrm{v}_{\mathrm{QA}} \cdot \mathrm{Z}_{\mathrm{Q}}$ \\
\hline 8. & Rain water & $\mathrm{Z}_{\mathrm{BR}}=\mathrm{Z}_{\mathrm{W}}+\mathrm{v}_{\mathrm{QA}} \cdot \mathrm{Z}_{\mathrm{Q}} \cdot Q$ \\
\hline 9. & Water & $\mathrm{Z}_{\mathrm{BW}}=\mathrm{Z}_{\mathrm{W}}+\mathrm{Z}_{\mathrm{P}} \cdot\left(\mathrm{C}_{\mathrm{PW}} / \rho_{\mathrm{OC}}\right)$ \\
\hline 10. & Soil & $\mathrm{Z}_{\mathrm{BS}}=\mathrm{v}_{\mathrm{AS}} \cdot \mathrm{Z}_{\mathrm{A}}+\mathrm{v}_{\mathrm{WS}} \cdot \mathrm{Z}_{\mathrm{W}}+\left\{\left(1-\mathrm{v}_{\mathrm{WS}}-\mathrm{v}_{\mathrm{AS}}\right) /\left[1+\left(\left(1-\mathrm{m}_{\mathrm{S}}\right) \rho_{\mathrm{OC}} /\left(\mathrm{m}_{\mathrm{S}} \cdot \rho_{\mathrm{MM}}\right)\right)\right]\right\} \cdot \mathrm{Z}_{\mathrm{P}}$ \\
\hline
\end{tabular}

Table 2: Mass balance equations for each phase

\begin{tabular}{lll}
\hline & Medium & Mass balance equations \\
\hline 1. & Air & $\mathrm{d}\left(\mathrm{V}_{\mathrm{A}} \mathrm{Z}_{\mathrm{BA}} \mathrm{Aq}_{\mathrm{A}}\right) / \mathrm{dt}=\mathrm{E}_{\mathrm{A}}+\mathrm{D}_{\mathrm{AIN}} \cdot \mathrm{Aq}_{\mathrm{AUT}}-\mathrm{Aq}_{\mathrm{A}} \cdot\left(\mathrm{D}_{\mathrm{AS}}+\mathrm{D}_{\mathrm{AW}}+\mathrm{D}_{\mathrm{AUT}}\right)$ \\
2. & Water & $\mathrm{d}\left(\mathrm{V}_{\mathrm{W}} \mathrm{Z}_{\mathrm{BW}} \mathrm{Aq}_{\mathrm{W}}\right) / \mathrm{dt}=\mathrm{E}_{\mathrm{W}}+\mathrm{D}_{\mathrm{AW}} \cdot \mathrm{Aq}_{\mathrm{S}}+\mathrm{D}_{\mathrm{SW}} \cdot \mathrm{Aq}_{\mathrm{S}}+\mathrm{D}_{\mathrm{WIN}} \cdot \mathrm{Aq}_{\mathrm{WUT}}-\mathrm{Aq}_{\mathrm{W}} \cdot\left(\mathrm{D}_{\mathrm{RW}}+\mathrm{D}_{\mathrm{WUT}}\right)$ \\
3. & Soil & $\mathrm{d}\left(\mathrm{V}_{\mathrm{S}} \mathrm{Z}_{\mathrm{BS}} \mathrm{Aq}_{\mathrm{S}}\right) / \mathrm{dt}=\mathrm{E}_{\mathrm{S}}+\mathrm{D}_{\mathrm{AS}} \cdot \mathrm{Aq}_{\mathrm{A}}-\mathrm{Aq}_{\mathrm{S}} \cdot\left(\mathrm{D}_{\mathrm{RS}}+\mathrm{D}_{\mathrm{SW}}\right)$ \\
\hline
\end{tabular}

Table 3 Equation used to calculate the dimensionless Z-values ${ }^{\mathrm{a}}$ 
Am. J. Applied Sci., 2 (7): 456-464

Table 4: Equation used to calculate the D-values in units of $\mathrm{m}^{3} / \mathrm{h}$

\begin{tabular}{|c|c|c|c|c|}
\hline \multicolumn{3}{|c|}{ Compartments } & \multirow[b]{2}{*}{ Process } & \multirow[b]{2}{*}{ Equation } \\
\hline From & To & & & \\
\hline \multirow[t]{3}{*}{ Air } & Water & 1. & Total & $\mathrm{D}_{\mathrm{AW}}=\mathrm{D}_{\mathrm{W}_{\mathrm{WD}}}+\mathrm{D}_{\mathrm{W}_{\mathrm{DD}}}$ \\
\hline & & 2. & Wet deposition of gases and particles & $\mathrm{D}_{\mathrm{W}_{\mathrm{WD}}}=\mathrm{G}_{\mathrm{W}_{\mathrm{AW}}} \cdot \mathrm{Z}_{\mathrm{BR}}$ \\
\hline & & 3. & Dry particle deposition & $\mathrm{D}_{\mathrm{W}_{\mathrm{DD}}}=\mathrm{U}_{\mathrm{DW}} \cdot \mathrm{v}_{\mathrm{QA}} \cdot \mathrm{Z}_{\mathrm{Q}} \cdot A_{\mathrm{W}}$ \\
\hline Air & Soil & 4. & Overall deposition & $\mathrm{D}_{\mathrm{AS}}=\mathrm{U}_{\mathrm{DS}} \cdot \mathrm{v}_{\mathrm{QA}} \cdot \mathrm{Z}_{\mathrm{Q}} \cdot \mathrm{A}_{\mathrm{S}}+\mathrm{G}_{\mathrm{W}_{\mathrm{AS}}} \cdot \mathrm{Z}_{\mathrm{BR}}$ \\
\hline Soil & Water & 5. & Water and solid runoff & $\mathrm{D}_{\mathrm{SW}}=\mathrm{G}_{\mathrm{w}_{\mathrm{sW}}} \cdot \mathrm{Z}_{\mathrm{W}}+\mathrm{G}_{\mathrm{P}_{\mathrm{SW}}} \cdot \mathrm{Z}_{\mathrm{S}}$ \\
\hline Losses & & 6. & Degradation & $\mathrm{D}_{\mathrm{DRX}}=V_{\mathrm{X}} \cdot \mathrm{Z}_{\mathrm{BX}} \cdot \mathrm{k}_{\mathrm{RX}}$ \\
\hline \multirow[t]{4}{*}{ Advections } & & 7. & Advection of air into model domain & $\mathrm{D}_{\mathrm{AIN}}=\mathrm{Z}_{\mathrm{BA}_{\mathrm{IN}}} \cdot \mathrm{G}_{\mathrm{A}}$ \\
\hline & & 8. & Advection of air out of model domain & $\mathrm{D}_{\mathrm{AIN}}=\mathrm{Z}_{\mathrm{BA}} \cdot \mathrm{G}_{\mathrm{A}}$ \\
\hline & & 9. & Advection of water into model domain & $\mathrm{D}_{\mathrm{WIN}}=\mathrm{Z}_{\mathrm{BW}_{\mathrm{IN}}} \cdot \mathrm{G}_{\mathrm{W}_{\mathrm{IN}}}$ \\
\hline & & 10. & Advection of water out of model domain & $\mathrm{D}_{\mathrm{WUT}}=\mathrm{Z}_{\mathrm{BW}} \cdot \mathrm{G}_{\mathrm{W}_{\mathrm{UT}}}$ \\
\hline
\end{tabular}

The input and output rates should be in units of amount/time, e.g., mol/h or g/h. The "contents" must be in consistent units, e.g., in mol or $g$, and $\mathrm{dt}$, the time increment, in units consistent with the time unit in the input and output terms, e.g., h. The differential equation can then be solved along with an appropriate initial or boundary condition to give algebraic expression for concentration as a function of time ${ }^{[18]}$.

Based on the (Eq. 3), contaminant fate in the current model is expressed with the help of one dynamic mass balance equation for each of the three model compartments. These equations are formulated in terms of aquivalence ${ }^{[16]}$, in units of $\mathrm{mol} / \mathrm{m}^{3}$, i.e. employ the concepts of Z-values, (dimensionless) to describe phase partitioning and D-values, in units of $\mathrm{m}^{3} / \mathrm{h}$ to describe contaminant fate processes. They thus take the generic form:

$$
\frac{\mathrm{d}\left(\mathrm{V}_{\mathrm{X}} \mathrm{BZ}_{\mathrm{X}} \mathrm{Aq}_{\mathrm{X}}\right)}{\mathrm{dt}}=\mathrm{E}_{\mathrm{X}}+\sum_{\mathrm{Y}} \mathrm{D}_{\mathrm{YX}} \times \mathrm{Aq}_{\mathrm{Y}}-\left(\sum_{\mathrm{Y}} \mathrm{D}_{\mathrm{XY}} \times \mathrm{D}_{\mathrm{RX}}\right) \times \mathrm{Aq}_{\mathrm{X}}
$$

In this equation, $\mathrm{V}_{\mathrm{X}}, \mathrm{Z}_{\mathrm{BX}}, \mathrm{Aq}_{\mathrm{X}}$ are the volume, bulk $\mathrm{Z}$ value and aquivalence of compartment $\mathrm{X}, \mathrm{D}_{\mathrm{XY}}$ and $\mathrm{D}_{\mathrm{YX}}$ are the D-values describing the transport processes delivering contaminant from compartment $\mathrm{Y}$ to compartment $\mathrm{X}$, and vice versa, $\mathrm{E}_{\mathrm{X}}$ is the emission rate into compartment $\mathrm{X}$ in $\mathrm{mol} / \mathrm{h}$, and $\mathrm{D}_{\mathrm{RX}}$ is the $\mathrm{D}$-value describing the degradation loss in compartment $\mathrm{X}$. The three differential mass balance equations are solved using a stepwise approach, with a finite difference approximation. The expressions for phase partitioning, inter-media transport and degradation build upon those from previous fugacity/aquivalence models ${ }^{[13,16,18-19]}$.

In the following context, details are provided for the calculation of the mass balance equations for each model compartment. These calculations are based on equation 4 and figure 1 .

The mass balance equation for Air: With two input rates to the atmospheric compartment (1) emission rate into air compartment, $\mathrm{E}_{\mathrm{A}}$ in $\mathrm{mol} / \mathrm{h}$, and (2) advection of air into model region, $\mathrm{D}_{\mathrm{AIN}}$ in $\mathrm{m}^{3} / \mathrm{h}$, and three loss rates (1) deposition of contaminant to terrestrial compartment, $\mathrm{D}_{\mathrm{AS}}$ in $\mathrm{m}^{3} / \mathrm{h}$, (2) deposition of contaminant to aquatic compartment, $\mathrm{D}_{\mathrm{AW}}$ in $\mathrm{m}^{3} / \mathrm{h}$, and (3) advection of air out of model region, $D_{\text {AUT }}$ in $\mathrm{m}^{3} / \mathrm{h}$, the mass balance equation for atmospheric compartment is calculated using Eq. (1) in Table 2.

The mass balance equation for water: With four input rates to the aquatic compartment (1) emission rate into water compartment, $\mathrm{E}_{\mathrm{W}}$ in $\mathrm{mol} / \mathrm{h}$, and (2) advection of water into model region, $D_{\text {WIN }}$ in $\mathrm{m}^{3} / \mathrm{h}$, (3) water runoff from soil compartment, $D_{\mathrm{SW}}$ in $\mathrm{m}^{3} / \mathrm{h}$, and (4) deposition of contaminant from atmospheric compartment, $\mathrm{D}_{\mathrm{AW}}$ in $\mathrm{m}^{3} / \mathrm{h}$, and two loss rates (1) degradation in water, $D_{R W}$ in $\mathrm{m}^{3} / \mathrm{h}$, and (2) advection of water out of model region, $D_{\text {WUT }}$ in $\mathrm{m}^{3} / \mathrm{h}$, the mass balance equation for aquatic compartment is calculated using Eq. (2) in Table 2. 
The mass balance equation for soil: With two input rates to the terrestrial compartment (1) emission rate into terrestrial compartment, $\mathrm{E}_{\mathrm{S}}$ in $\mathrm{mol} / \mathrm{h}$, and (2) deposition of contaminant from atmospheric compartment, $\mathrm{D}_{\mathrm{AS}}$ in $\mathrm{m}^{3} / \mathrm{h}$, and two loss rates (1) water run-off to aquatic compartment, $\mathrm{D}_{\mathrm{SW}}$ in $\mathrm{m}^{3} / \mathrm{h}$, and (2) degradation in soil, $D_{R S}$ in $\mathrm{m}^{3} / \mathrm{h}$, the mass balance equation for terrestrial compartment is calculated using Eq. (3) in Table 2.

These mass balance equations are needed to evaluate the partitioning of chemicals in the agricultural environment, and to calculate the overall persistence, concentration, and amount of chemicals in each environmental phase.

In the following, details are provided for how the various $Z$ and $D$-values are calculated in the current model.

Description of phase partitioning: As ideal for fugacity/aquivalence models ${ }^{[20]}$, equilibrium phase partitioning in the current model is expressed in terms of Z-values or the compartment capacities. The Zvalues for NVOC are calculated using the aquivalence approach. As discussed previously, this approach was developed by Mackay and co-workers ${ }^{[14]}$. The derivation of aquivalence approach as a criterion of equilibrium are fully described elsewhere ${ }^{[18]}$ and are only briefly summarized here.

Mackay et al. 1996b have described that the capacity of water compartment $\left(Z_{W}\right)$ for all NVOC is first defined as 1.0 and all other $Z$-values, including that for aerosols, are deduced as:

$\mathrm{Z}_{\mathrm{X}}=\mathrm{K}_{\mathrm{XW}} \cdot \mathrm{Z}_{\mathrm{W}}$

It is desirable to calculate a Z-value for bulk phase consisting of other phases at equilibrium. The use of bulk Z-values helps to simplify calculations by reducing the number of compartments ${ }^{[18]}$. The bulk Zvalue for a compartment $j,\left(Z_{\mathrm{Bj}}\right),($ Eq. 2$)$ is an average of the compartment capacity, $Z_{j}$, of the various gaseous, aqueous and solid sub-phases making up this compartment, weighted by the volume fraction of these sub phases.

$\mathrm{Z}_{\mathrm{Bj}}=\sum \mathrm{v}_{\mathrm{ij}} \cdot \mathrm{Z}_{\mathrm{j}}$

where $v_{\mathrm{ij}}$ is the volume fraction of sub-phase $i$ in phase $j, \mathrm{~m}^{3} / \mathrm{m}^{3}$, and $\mathrm{Z}_{\mathrm{j}}$ is the dimensionless capacity of phase $j$.

In the subsequent, details are provided for the phase partitioning in each of three model compartment.

Phase partitioning in the aqueous system: As discussed previously, the capacity of pure water $Z_{W}$ is defined as 1.0. Particulate organic carbon (POC) in water is important, like aerosols in the atmosphere; it serves as a vehicle for the transport of contaminants from the bulk of the water to bottom sediment ${ }^{[18]}$. The $\mathrm{Z}$-value for POC, $Z_{\mathrm{P}}$ (Eq. (4) in Table 3), is a product of the POC to water partition coefficient, $K_{\mathrm{P}}$ in $(\mathrm{L} / \mathrm{kg})$, and the capacity of pure water ${ }^{[21]}$. The bulk $Z$-value for water compartment $\left(Z_{\mathrm{BW}}\right)$ is calculated using Eq. (10) in Table 3 , where $\mathrm{C}_{\mathrm{PW}}$ is the concentration of POC in the water column, were previously derived as part of the POC mass balance.

Phase partitioning in the air phase: Based on Eq. (5), the capacity of atmospheric compartment, $\mathrm{Z}_{\mathrm{A}}$ is calculated from air-water partition coefficient $\left(K_{\mathrm{AW}}\right)$ (Eq. (1) in Table 3). Definition of a zero $K_{\mathrm{AW}}$, which results in $Z_{\mathrm{A}}$ being zero, is acceptable. The $\mathrm{Z}$-value for atmospheric particles, $Z_{\mathrm{Q}}$, is calculated using Eq. (2) in Table 3. In this equation, $K_{\mathrm{QW}}$ is the (hypothetical) aerosol-water partition coefficient. Mackay et al. 1996b have suggested a value for (hypothetical) $K_{\mathrm{QW}}$ of 100 , causes the entire chemical in the atmosphere to be associated with aerosol particles. Changing this value of 100 has no significant effect on chemical fate. The bulk $\mathrm{Z}$-value for the atmosphere is calculated using Eq. (8) in Table 3. In this equation, $v_{\mathrm{QA}}$ represent the volume fractions of aerosol in air. If the concentration of aerosols or total suspended particulates is TSP $\mathrm{ng} / \mathrm{m}^{3}$, this corresponds to $10^{-12} \mathrm{TSP} \mathrm{kg} / \mathrm{m}^{3}$ and to a volume fraction of

$v_{\mathrm{QA}}=\frac{10^{-12} \mathrm{TSP}}{\frac{\rho_{\mathrm{Q}}}{1000}}$

where $\rho_{\mathrm{Q}}$ is the aerosol density in $\mathrm{kg} / \mathrm{m}^{3}{ }^{[18]}$. The rain bulk Z-value is calculated using Eq. (9) in Table 3, where $\mathrm{Q}$ is the particle scavenging ratio.

Phase partitioning in the soil phase: The capacity of soil compartment, $Z_{S}$ is calculated from soil-water partition coefficient $\left(\mathrm{K}_{\mathrm{SW}}\right)$ (Eq. (5) in Table 3). Soil is a composite of air, water and solids. The non-organic fraction of the solids is assumed to make a negligible contribution to the bulk Z-value for soils. Thus, the soil bulk Z-value is calculated using Eq. (11) in Table 3. In this equation, $v_{\mathrm{AS}}, v_{\mathrm{WS}}$, and the term in wavy brackets are the volume fraction of air, water, and particulate organic carbon in bulk soil, respectively, where $\rho_{\mathrm{mm}}$, $\rho_{\mathrm{OC}}$ is the density of mineral matter, and organic carbon, respectively in $\mathrm{g} / \mathrm{m}^{3}$, and $\mathrm{m}_{\mathrm{S}}$ is the mass fraction of organic carbon in solids of soil compartment. 
Description of chemical fate processes: Transport and degradation processes in aquivalence-based models are described with the help of D-values in units of $\mathrm{m}^{3} / \mathrm{h}^{[16]}$. The group G Z, and other like it, appear so frequently in later calculations that it is convenient to designate them as $\mathrm{D}$-values, i.e., $\mathrm{D}=\mathrm{U} \cdot \mathrm{A}_{\mathrm{X}} \cdot \mathrm{Z}_{\mathrm{X}}$

where $U$ is the intermedia transport parameter, i.e., mass transfer coefficient in $\mathrm{m} / \mathrm{h}, \mathrm{A}_{X}$ is the surface area of compartment $X$ in $\mathrm{m}^{2}$, and $Z_{X}$ is the dimensionless capacity of compartment $X$.

Description of air-surface exchange: In air-surface exchange, there can be deposition by the parallel processes of (1) dry particle deposition, (2) wet particle deposition, (3) rain dissolution, i.e. the dissolution of contaminant in the falling rain drops (wet gaseous deposition), and (4) diffusive absorption-volatilization. Since the current model is fairly applicable to NVOC that have a negligible or zero vapor pressure, the model thus neglects the absorption-volatilization process.

Aerosol particles have a very high surface area and thus sorb many pollutants, especially those of a very low vapor pressure. Dry particle deposition occurs when gases and aerosol particles are intercepted by the earth's surface under the influence of gravity in the absence of precipitation. Deposition velocity, is quite slow and depends on the turbulent condition of the atmosphere; size and properties of the aerosol particle; the nature of the ground surface. Typical velocity is about $0.3 \mathrm{~cm} / \mathrm{s}$ or $10.8 \mathrm{~m} / \mathrm{h}$.

Rain is often highly contaminated with substances, and often much more contaminated than surface water. Wet particle deposition is by washout of contaminant sorbed onto particles by precipitation. It is directly proportional to the concentration of pollutant in the rain phase. The concentration of pollutants in wet deposition is due to two important effects with quite different physical mechanisms: aerosol particle scavenging, and gas scavenging ${ }^{[22]}$. Wet deposition is about twice the dry deposition.

Description of air-water exchange: Wet deposition of gaseous and particle-bound substances is treated as an advective transport process, and the D-value is calculated using Eq. (2) in Table 4. In this equation, $\mathrm{G}_{\mathrm{W}_{\mathrm{AW}}}$ is the product of the rain water flow to the water surface in $\mathrm{m}^{3} / \mathrm{h}$ (Eq. (3) in Table 1), and $Z_{\mathrm{BR}}$ is the dimensionless bulk Z-value of rain (Eq. (9) in Table 3). The D-value for dry particle deposition, $\mathrm{D}_{\mathrm{W}_{\mathrm{DD}}}$ is calculated using Eq. (3) in Table 4, where $A_{W}$ is the water compartment surface area, $\mathrm{m}^{2}$, and $\mathrm{U}_{\mathrm{DW}}$ is the dry particle deposition velocity to water compartment in $\mathrm{m} / \mathrm{h}$. This velocity is volumetric rate of particle transport:

$\mathrm{U}_{\mathrm{DW}}=\frac{\mathrm{G}_{\mathrm{Q}}}{\mathrm{A}_{\mathrm{W}}}$

where $G_{Q}$ is the flow of aerosol deposited to water compartment, $\mathrm{m}^{3} / \mathrm{h}$. Thus, summing of the D-values for wet deposition of gaseous and particle and dry particle deposition (Eqs. (2) and (3) in Table 4) yields the overall D-values for atmospheric deposition to water (Eq. (1) in Table 4).

Description of air-soil exchange: By analogy with the overall D-value for atmospheric deposition to soil is calculated using Eq. (4) in Table 4. In this equation, $A_{S}$ is the soil compartment surface area, $\mathrm{m}^{2}, \mathrm{G}_{\mathrm{W}_{A S}}$ is the product of the rain water flow to the soil surface in $\mathrm{m}^{3} / \mathrm{h}$ (Eq. (2) in Table 1), and $U_{D S}$ is the dry particle deposition velocity to soil compartment in $\mathrm{m} / \mathrm{h}$, which calculated similar to $U_{D W}$, (Eq. 9) with considering the surface area for soil but not for water.

Description of soil-water exchange: Contaminants may be transferred from soil to water through solids or water runoff. The D-values for these processes are calculated using Eq. (5) in Table 4. In this equation, $\mathrm{G}_{\mathrm{w}_{\mathrm{sw}}}$ is the run-off flux from soil to water in $\mathrm{m}^{3} / \mathrm{h}$ (Eq. (6) in Table 1), and $\mathrm{G}_{\mathrm{P}_{\mathrm{SW}}}$ is the inflow of POC from soil to water in $\mathrm{m}^{3} / \mathrm{h}$ (Eq. (10) in Table 1).

Description of loss processes: The loss or removal processes for a contaminant are the reaction (degradation). Mackay, 2001 has used a simple firstorder kinetic expression for all reactions. The basic rate equation is:

Rate $\mathrm{N}=\mathrm{V} \cdot \mathrm{C} \cdot \mathrm{k}=\mathrm{M} \cdot \mathrm{k} \quad \mathrm{mol} / \mathrm{h}$

where $\mathrm{V}$ is the phase volume in $\mathrm{m}^{3}, \mathrm{C}$ is the concentration of the chemical in $\mathrm{mol} / \mathrm{m}^{3}, \mathrm{M}$ is the amount of chemical, and $\mathrm{k}$ is the first-order rate constant with units of reciprocal time.

Reaction rates increase with increasing temperature. Svante Arrhenius determined the relationship between the reaction rate constant and temperature

$\mathrm{k}=\mathrm{A} \cdot \exp ^{-\frac{\mathrm{AE}}{\mathrm{RT}}}$

where $\mathrm{A}$ is a constant that is characteristic of the reaction, $\mathrm{AE}$ is the activation energy of the degradation 
reaction in $\mathrm{J} / \mathrm{mol}, \mathrm{T}$ is the absolute temperature in $\mathrm{K}$, and $\mathrm{R}$ is the ideal gas constant in $\mathrm{J} /(\mathrm{K} \cdot \mathrm{mol})$.

Occasionally, it is desirable to convert a rate constant from a known or reference temperature to a second temperature. In this case, Eq. (11) can be used for two different temperatures, the equations for $k$ equated, and the constant $\mathrm{A}$ drops out ${ }^{[22]}$.

$k_{\mathrm{T}_{1}}=k_{\mathrm{T}_{2}} \cdot \exp ^{\frac{A E}{\mathrm{R}} \cdot\left(\frac{1}{\mathrm{~T}_{1}}-\frac{1}{\mathrm{~T}_{2}}\right)}$

In the current model, all degradation rates are calculated as a function of compartment temperature using a contaminant-specific degradation rate $k_{\mathrm{DRX}}$ at the reference temperature $25^{\circ} \mathrm{C}$ and activation energy $A E_{\mathrm{X}}$. Thus,

$k_{\mathrm{RX}}=k_{\mathrm{DRX}} \cdot \exp ^{\frac{A E_{\mathrm{X}}}{\mathrm{R}} \cdot\left(\frac{1}{\mathrm{~T}}-\frac{1}{T_{\mathrm{X}}}\right)}$

This degradation rate is assumed to include all degradation processes that the chemical can undergo, including biodegradation, hydrolysis, and photolysis. Thus, the D-values describing degrading reactions in each model compartments are calculated using Eq. (8) in Table 4. In the later expression, the D-values are calculated using the bulk-phase Z-values, degradation rates for the bulk compartment and not for a specific phase.

Description of advection processes: The D-values for advected air into/out of model domain, (Eqs. (7), (8) in Table 4) is the product of the transfer rate of the air $G_{A}$, (Eq. (1) in Table 1) in units of $\mathrm{m}^{3} / \mathrm{h}$, and its dimensionless bulk Z-value, $Z_{\mathrm{BA}}$ (Eq. (8) in Table 3). The D-values for advected water into/out of model domain, (Eqs. (9), (10) in Table 4) is the product of the water flow from outside to model domain and vice versa, (Eqs. (8), (9) in Table 1) in units of $\mathrm{m}^{3} / \mathrm{h}$, and its dimensionless bulk Z-value, $Z_{\mathrm{BW}}$ (Eq. (10) in Table 3).

Overall persistence, concentration, and total amount: Environmental persistence is an important criterion when assessing chemical contaminants ${ }^{[23]}$. The overall environmental persistence may be predicted as the total amount of chemical in the environment at steady state divided by the total loss rate $\mathrm{r}^{[24]}$. In the current, the overall persistence $\tau$ (h) is calculated using the following expression:

$$
\tau=\frac{\sum_{X} \mathrm{Aq}_{\mathrm{X}} \cdot \mathrm{V}_{\mathrm{X}} \cdot \mathrm{Z}_{\mathrm{BX}}}{\sum_{\mathrm{X}} \mathrm{Aq}_{\mathrm{X}} \cdot \mathrm{D}_{\mathrm{RX}}}
$$

where $\mathrm{Aq}_{\mathrm{X}}$ is the equilibrium criterion (aquivalence) in $\mathrm{mol} / \mathrm{m}^{3}, V_{X}$ is the volume of compartment $\mathrm{X}$ in $\mathrm{m}^{3}, \mathrm{Z}_{\mathrm{BX}}$ is the dimensionless bulk Z-value for compartment $\mathrm{X}$, and $D_{R X}$ is the degradation in compartment $X$ in $\mathrm{m}^{3} / \mathrm{h}$.

The concentration of chemical $\left(\mathrm{mol} / \mathrm{m}^{3}\right)$ in compartment $\mathrm{X}$ is the product of the dimensionless compartment capacity $\mathrm{Z}_{\mathrm{X}}$, and its relative aquivalence $\mathrm{Aq}_{\mathrm{X}}$ in units of $\mathrm{mol} / \mathrm{m}^{3}$.

The total amount of chemical in compartment $\mathrm{X}$ in mol is the product of dimensionless bulk compartment capacity $Z_{\mathrm{BX}}$, compartment volume in $\mathrm{m}^{3}$, and its relative aquivalence $A q_{X}$ in units of $\mathrm{mol} / \mathrm{m}^{3}$.

\section{RESULTS AND DISCUSSION}

The use of this model, intermedia fluxes of organic chemicals between air, water, and soil at steady-state, partitioning, overall persistence, total amount, and total concentrations at dynamic conditions can be calculated. The results of these calculations are useful to decision makers because this model provides an appropriate quantitative framework to evaluate our understanding of the complex interactions between chemicals and the agricultural environment. It is introduced to set clean-up standards, to assess the relative importance of chemical emissions, to evaluate the partitioning, persistence, long-range transport of non-volatile organic pollutants, and set priorities in agricultural pollution prohibition.

\section{CONCLUSION}

A MFTM at non-steady state conditions has been developed that incorporates mechanisms of NVOC transport and transformation in the agricultural environment. The model, an adaptation of Mackay's Level IV aquivalence model, includes the air, surface water, and agricultural soil compartments. Current model aimed to evaluate the fate of NVOC in the major surfaces compartments for agricultural environment. In addition to the model usage benefits mentioned above, we believe that the model is a useful first step towards improving our understanding of the influence of the built environment on chemical fate.

\section{ACKNOWLEDGEMENTS}

The authors would like to thank the Malaysian Ministry of Science, Technology and Innovation (MOSTI) for funding this study. 


\section{REFERENCES}

1. Edwards, C.A., 1973. Persistent pesticides in the environment. Vol. 2. United States

2. Gil, Y. and Sinfort, C., 2005. Emission of pesticides to the air during sprayer application: A bibliographic review. Atmospheric Environment, 39: 5183-5193

3. Alegria, H., Bidleman, T.F. and Figueroa, M.S., 2005. Organochlorine pesticides in the ambient air of Chiapas, Mexico. Environmental Pollution, 140: 483-491

4. Briand, O., Bertrand, F., Seux, R. and Millet, M., 2002. Comparison of different sampling techniques for the evaluation of pesticide spray drift in apple orchards. The Science of the Total Environment, 288: 199-213

5. Voutsas, E., Vavva, C., Magoulas, K. and Tassios, D., 1983. Estimation of the volatilization of organic compounds from soil surfaces. Chemosphere, 58: 751-758

6. Brady, J.A., Wallender, W.W., Werner, I., Fard, M.B., Zalom, F.G., Oliver, M.N., Wilson, B.W., Mata, M.M., Henderson, J.D., Deanovic, L.A. and Upadhaya, S., 2006. Pesticide runoff from orchard floors in Davis, California, USA: A comparative analysis of diazinon and esfenvalerate. Agriculture, Ecosystems \& Environment, 115: 56-68

7. Si, Y., Zhang, J., Wang, S., Zhang, L. and Zhou, D., 2006. Influence of organic amendment on the adsorption and leaching of ethametsulfuron-methyl in acidic soils in China. Geoderma, 130: 66-76

8. Swann, R.L. and Eschenroeder, A., 1983. Fate of chemicals in the environment. American chemical society. Washington

9. Bending, G.D., Lincoln, S.D. and Edmondson, R.N., 2006. Spatial variation in the degradation rate of the pesticides isoproturon, azoxystrobin and diflufenican in soil and its relationship with chemical and microbial properties. Environmental Pollution, 139: 279-287

10. Wania, F. and McLachlan, M.S., 2001. Estimating the influence of forests on the overall fate of semivolatile organic compounds using a multimedia fate model. Environmental Science \& Technology 35: 582-590

11. Diamond, M.L., Priemer, D.A. and Law, N.L., 2001. Developing a multimedia model of chemical dynamics in urban area. Chemosphere, 44: 16551667
12. Zhang, Q., Crittenden, J.C., Shonnard, D. and Mihelcic, J.R., 2003. Development and evaluation of an environmental multimedia fate model CHEMGL for the Great Lakes region. Chemosphere, 50:1377-1397

13. Wania, F., Breivik, K., Persson, N. J. and McLachlan, M.S., 2006. CoZMo-POP 2 - A fugacity-based dynamic multi-compartmental mass balance model of the fate of persistent organic pollutants. Environmental modeling \& software, 21: 868-884

14. Mackay, D. and Diamond, M., 1989. Application of the QWASI (Quantitative Water Air Sediment Interaction) fugacity model to the dynamics of organic and inorganic chemicals in lakes. Chemosphere 18: 1343-1365

15. Mackay, D., Di Guardo, A., Paterson, S., Kicsi, G. and Cowan, C E., 1996a. Assessing the fate of new and existing chemicals: a five-stage process. Environmental Toxicology \& Chemistry, 15: 16181626

16. Mackay, D., Di Guardo, A., Paterson, S. and Cowan, C.E., 1996b. Evaluating the environmental fate of a variety of types of chemicals using the EQC model. Environmental Toxicology \& Chemistry, 15: 1627-1637

17. Mackay, D., Di Guardo, A., Paterson, S., Kicsi, G., Cowan, C E. and Kane, D.M., 1996c. Assessment of chemical fate in the environment using evaluative, regional and local scale models: illustrative application to chlorobenzenes and linear alkylbenzene sulfonates. Environmental Toxicology \& Chemistry, 15: 1638-1648

18. Mackay, D., 2001. Multimedia Environmental Models: The Fugacity Approach. Lewis Publishers, Chelsea, MI

19. Warren, C.S., Mackay, D., Bahadur, N.P. and Boocock, D.G.B., 2002. A suite of multi-segment fugacity models describing the fate of organic contaminants in aquatic systems: application to the Rihand Reservoir, India. Water Research, 36: 4341-4355

20. Mackay, D., 1991. Multimedia Environmental Models. Lewis Publishers, Boca Raton, FL

21. Freitas, H., Diamond, M., Semkin, R., Gregor, D., 1997. Contaminant fate in high arctic lakes: development and application of a mass balance model. The Science of the Total Environment, 201: 171-187

22. Schnoor, J.L., 1996. Environmental modeling: fate and transport of pollutants in water, air, and soil. John Wiley \& Sons, Inc. New York

23. Webster, E., Mackay, D. and Wania, F., 1998. Evaluating environmental persistence. Environmental Toxicology \& Chemistry, 17: 21482158

24. Zukowska, B., Breivik, K. and Wania, F., 2006. Evaluating the environmental fate of pharmaceuticals using a level III model based on poly-parameter linear free energy relationships. Science of the Total Environment, 359: 177- 187. 